\title{
Global Perspectives
}

Vladimir Hachinski, MD, DSc, FAAN

Correspondence \& reprint requests to Dr. Hachinski: Vladimir.hachinski@lhsc.on.ca
THE WORLD FEDERATION OF NEUROLOGY: THE WAY FORWARD

Continuity and change describe the activities of the current administration. The continuity is reflected in the successful congresses, our publications, including World Neurology and the Journal of Neurological Sciences, and its educational activities, including CONTINUUM for developing countries, a joint program with the American Academy of Neurology. We are building on the work carried out by my predecessor as President, Johan Aarli, who has a longstanding record of working closely with the WHO. He was a key participant in the projects that led to the publication of the WHO monograph "Neurological disorders: public health challenges" (2006) and Atlas: Country Resources for Neurological Disorders. The WHO is revising the International Classification of Diseases (ICD-10). Our Secretary General, Raad Shakir, is Chair of the Neurology Expert Committee adyising on the revisions to ICD-10 that will lead to the ICD-11. Bo Norrving, President of the World Stroke Organization, chairs the Stroke Subcommittee. Stroke no longer will be listed under "cardiovascular diseases," but appropriately under the brain, a remarkable achievement, given the long struggle that this has entailed.

Donna Bergen, Chair, Applied Research Committee, represents us at a major WHO initiative. The World Federation of Neurology (WFN) recently joined nearly 50 other major international organizations at the second meeting of the WHO's mhGAP Action Programme: Scaling up Care for Mental, Neurological and Substance Use Disorders (http:// www.who.int/mental_health/mhgap/enindex.html).

When I was Vice President, I began a process that resulted in moving the World Congresses from a 4to a 2-year cycle. The main purpose is to take neurology to those who cannot travel internationally. For the first time in its history, a World Congress of Neurology will be held on the African continent, a tangible result of Johan Aarli's Africa initiative. Beyond the already planned meetings of Marrakesh in

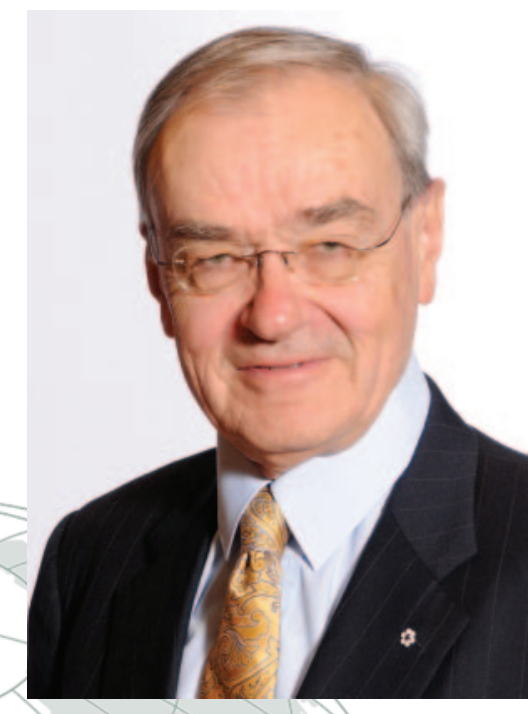

Vladimir Hachinski, MD, DSc, FAAN

2011 and Vienna in 2013, our vision is to hold the next World Congress of Neurology in South America in 2015 and Asia in 2017.

In July 2010, a Planning and Priorities Retreat was held in London, UK, and the WFN mission was redefined as "to foster quality neurology and brain health worldwide." The practical implications of the mission are that we aim to integrate, prioritize, and help apply advances in brain disease and brain health worldwide, in partnership with other organizations.

For the first time, we began a process of inviting projects from our membership, subjecting them to peer review, and then funding them either alone or with other organizations. The criteria used included the following: the value of projects (return per effort or funding), synergy within the WFN and with other organizations, viability, in terms of how the project will be sustained, and evaluation, how will the results be judged. What gets measured gets done. The winning projects and members were as follows:

- Bringing EMG/NCV capacity to Zambia: Professor Masharip Atadzhanov

- Educational grant for Asian Neurology: Professor Ryuji Kaji

- Stroke infrastructure survey: Dr. Philip Gorelick 
- Revision of ICD-10: Drs. Donna Bergen and Raad Shakir

- Cognitive clinics worldwide: Dr. Thomas Bak

- Neurology training in Afghanistan: Dr. Mohammad Wasay

- Pediatric neurology electronic training tool: Dr. Douglas Postels

- Training and retaining child neurologists: Dr. Jo Wilmshurst

- Children with epilepsy: Dr. Jo Wilmshurst

- Neurological education for non-neurologists: Dr. Barbara Scherokman

The leadership of the WFN saw an opportunity in the fact that the General Assembly of the United Nations has made non-communicable diseases (NCDs) a priority to form a World Brain Alliance to assure that the brain and its disorders, which represent a large percentage of premature deaths and disability, be part of the UN agenda. Such an alliance was formed in Geneva on March 30, 2011, and is comprised of the following:

- World Federation of Neurology

- World Federation of Neurosurgeons

- World Psychiatry Association

- International Brain Research Organization

- International Child Neurology Association

- World Federation of Neurorehabilitation

- European Brain Council

- International League Against Epilepsy

- World Stroke Organization

- Alzheimer International

Subsequently, the President of the WFN represented the Alliance at the First Global Ministerial Conference on Healthy Lifestyles and NonCommunicable Disease Control (Moscow, April 28-29, 2011), at the Civil Society informal interactive hearing on NCDs at the United Nations in New York City on June 16, 2011, and at the UN Summit on NCD held in New York, September 19 and 20, 2011. Through the efforts of the World Brain Alliance and other organizations, the Political Declaration of the High-level Meeting of the General Assembly on the Prevention and Control of Non-Communicable Diseases contains a paragraph that states "Recognize that mental and neurologic disorders, including $\mathrm{AD}$, are an important cause of morbidity and contribute to the global noncommunicable disease burden, for which there is a need to provide equitable access to effective programs and health-care interventions." However, the identified focus will remain on 4 major diseases, namely, cardiovascular disease, pulmonary disease, diabetes, and cancer, and on the control of tobacco and alcohol addiction, unhealthy diets, and physical inactivity. The WFN in collaboration with the World Stroke Orga- nization has advocated the spelling out of "cardiovascular disease" as "heart disease and stroke," a position also taken by the Lancet Group on NonCommunicable Diseases. The World Brain Alliance has argued that the risk factors that are targeted to be controlled are all behaviors mediated through the brain, and it has offered the expertise of its members to make sure that the implementation of these policies has the highest probability of success.

The World Brain Alliance is working toward making the brain, its health, and its disorders the subject of a future United Nations General Assembly meeting. As part of this effort, a World Brain Summit is being planned for 2014, Europe's "Brain Year," to create a platform involving professional organizations, industry, patient groups, and the public in an effort to set a World Brain Agenda.

Quality neurology implies standards. To this end, the WFN has created the Task Force on Standards, Evaluations and Accreditation, made up of Aksel Siva (Turkey) (Chair), Sarosh Katrak (India), and Charles Warlow (UK). They review applications for endorsements of Congresses and meetings and only do so if their judgment is that a meeting would benefit neurologists, has value, and is worthwhile.

All Trustees hold portfolios. Vice President Werner Hacke (Germany) is in charge of the Congress Committee, Secretary General Raad Shakir presides over ongoing operations, Stephen Sergay (USA) and Wolfgang Grisold (Austria) cochair the Education Committee, and Donna Bergen (USA) is the Chair of the Applied Research Committee and reviews the relationship of the WFN with other organizations. Ryuji Kaji (Japan) leads the Asia initiative, Alfred Njamnshi (Cameroon) leads the Africa Initiative, and Gustavo Roman (USA) leads the Latin American initiative. The continental initiatives are meant to identify opportunities for fostering neurology in underserviced areas of the world.

Although this administration was elected for a 4-year period, all appointments have been made for 2 years, including Trustees portfolios, Chairs of Committees, and Task Forces, and also membership of these Task Forces and Committees. The purpose is to allow for flexibility and create more opportunities for participation by a larger number of individuals.

The decision to move the World Neurology Congresses to a 2-year cycle has had a number of beneficial effects. We can go to more places in the world to make a difference, it is easier to sustain activities between congresses, and the more frequent congresses allow for closer interaction with other organizations. The Marrakesh World Congress of Neurology, held in November 12-17, 2011, illustrated some of these 
features. 1) We are making a special effort to attract neurologists from sub-Saharan Africa and to that effect, registration fees have been minimized for them and they have been provided with the largest proportion of traveling fellowships. 2) A special meeting has been called by Vice President Werner Hacke and Donna Bergen (Chair of the Applied Research Committee) to explore with subspecialty neurology and related organizations the possibilities of integration and collaboration. 3) The WFN has made a commitment that a portion of the revenues from the congress will be devoted to projects in Africa. The recommendations of the Website Task Force led by Werner Hacke will come to fruition in Marrakesh with the launching of a new website under the editorship of Jerome (Pete) Engel (USA).

A future change is that Dr. Robert Lisak, Editor of the Journal of Neurological Sciences, will end his long and distinguished Editorship in 2012. The search is open for a successor, and we encourage you to consider this highly rewarding and influential job by expressing interest to Chris Kennard (UK), Chair of the Publications Committee (chris.kennard@clneuro.ox.ac.uk).

Let us know of activities that you are undertaking in world neurology, particularly in developing countries, or an interest you may have in participation, so that we can see whether we can link you up with other interested parties to make a difference. If your interest falls clearly within one of the major committees, contact the chairs directly: Education Committee, Stephen Sergay (sergay1@juno.com) and Wolfgang Grisold (wolfgang.grisold@wienkav.at); Applied Research, Donna Bergen (donna_bergen@ rush.edu); otherwise, you can be in touch with me (Rebecca.clarke@lhsc.on.ca).

Given the growing needs for neurology in a shrinking world economy, our tasks are formidable, but so are our opportunities. 


\title{
Neurology
}

\author{
The World Federation of Neurology: The way forward \\ Vladimir Hachinski \\ Neurology 2012;78;286-288 \\ DOI 10.1212/WNL.0b013e31824367ec
}

This information is current as of January 23, 2012

\section{Updated Information \& Services}

Citations

Permissions \& Licensing

Reprints including high resolution figures, can be found at: http://n.neurology.org/content/78/4/286.full

This article has been cited by 1 HighWire-hosted articles: http://n.neurology.org/content/78/4/286.full\#\#otherarticles

Information about reproducing this article in parts (figures,tables) or in its entirety can be found online at:

http://www.neurology.org/about/about_the_journal\#permissions

Information about ordering reprints can be found online: http://n.neurology.org/subscribers/advertise

Neurology ${ }^{\circledR}$ is the official journal of the American Academy of Neurology. Published continuously since 1951, it is now a weekly with 48 issues per year. Copyright Copyright (? 2012 by AAN Enterprises, Inc.. All rights reserved. Print ISSN: 0028-3878. Online ISSN: 1526-632X.

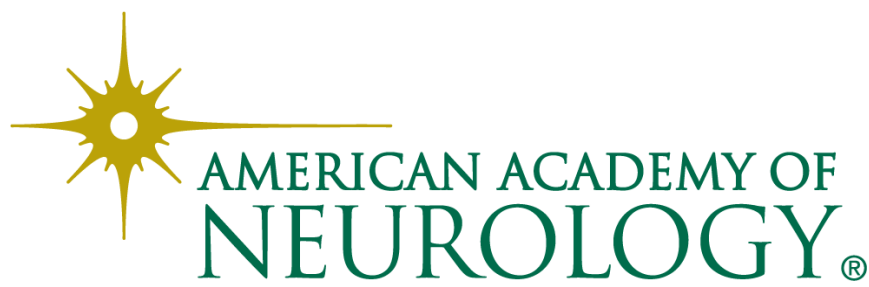

